Pacific Journal of Mathematics

COMPLEX BASES OF CERTAIN SEMIPROPER 


\title{
COMPLEX BASES OF CERTAIN SEMI-PROPER HOLOMORPHIC MAPS
}

\author{
ToshIo UDA
}

\begin{abstract}
The existence theorem of complex bases of quasi-proper holomorphic maps was studied by $\mathrm{N}$. Kuhlmann. In this paper the existence of the complex bases in a more general case will be shown.
\end{abstract}

o. Introduction. In the function theory of several complex variables, the complex bases of holomorphic maps of analytic spaces have been introduced as a generalized concept of Riemann surfaces defined by inverse functions of given holomorphic functions of one complex variable.

Let $f: X \rightarrow Y$ be a holomorphic map of analytic spaces. How does $f$ have a complex base? Authors have discussed the sufficient conditions which allow for the existence of a complex base of $f$ (cf. for example, [3], [5], [6], [7]). If $f$ is proper, then $f$ has a complex base ([7]). N. Kuhlmann [3] showed existence theorems in the case of quasi-proper ( $N$-quasi-proper). $f$ is called quasi-proper (resp. $N$-quasi-proper) if, for every compact subset $K$ of $Y$, there exists a compact subset $\widetilde{K}$ of $X$ such that each of the irreducible branches (resp. each of the connected components) of fibres on $K$ intersects $\widetilde{K}$.

On this subject, an attempt will be made to abate the condition, so that each of the given unions of connected components of fibres intersects $\widetilde{K}$. For such holomorphic maps, we shall have an existence theorem of complex bases (of type of N. Kuhlmann's).

TheOREM. Let $X$ be an irreducible normal analytic space, $f$ : $X \rightarrow Y$ be a holomorphic map of $X$ into an analytic space $Y$ and $E_{f}$ be the set of degeneracy of $f$. Suppose that $f$ satisfies $(C)$ and that $f\left(E_{f}\right)$ is analytic in $Y$. Then $f$ has a complex base $(\widetilde{Z}, \tilde{\varphi})$ and $\widetilde{Z}$ is also normal. Moreover, the natural holomorphic map $\widetilde{\psi}$ with $f=\tilde{\psi} \circ \tilde{\varphi}$ is proper and light, and $\tilde{\varphi}$ satisfies $\left(C_{1}\right)$.

1. Preliminaries. We assume in this paper that all analytic spaces are reduced and have countable bases of open sets.

Let $f: X \rightarrow Y$ and $f_{1}: X \rightarrow Y_{1}$ be holomorphic maps of analytic spaces. $f_{1}$ is said to strictly depend on $f$, if $f_{1}$ is constant on each connected component of fibres of $f . f_{1}$ is said to be analytically related to $f$, if $f$ and $f_{1}$ strictly depend on each other. A pair $(Z, \varphi)$ is called a complex base of $f$, if $Z$ is an analytic space, and 
if $\varphi: X \rightarrow Z$ is a surjective holomorphic map which is analytically related to $f$, and if, for each holomorphic map $h: X \rightarrow T$ which strictly depends on $f$, there exists a unique holomorphic map $\psi: Z \rightarrow T$ with $h=\psi \circ \varphi$.

A holomorphic map $f: X \rightarrow Y$ is said to be semi-proper, if, for each compact subset $K$ of $Y$, there exists a compact subset $\widetilde{K}$ of $X$ such that $f^{-1}(y) \cap \widetilde{K} \neq \varnothing$, for $y \in K \cap f(X) ; f$ is said to be quasiproper if $B \cap \widetilde{K} \neq \varnothing$, for each irreducible branch $B$ of $f^{-1}(y)$. N. Kuhlmann modified this definition ([3]); $f$ is said to be $N$-quasiproper, if $N \cap \widetilde{K} \neq \varnothing$, for each connected component $N$ of $f^{-1}(y)$. He showed the existence of complex bases of $\mathrm{N}$-quasi-proper holomorphic maps in [3].

Now, we consider a more general case in which each of the given unions of connected components of $f^{-1}(y)(y \in K \cap f(X))$ intersects $\widetilde{K}$.

Definition. A holomorphic map $f: X \rightarrow Y$ is said to satisfy $(C)$ if $f$ has the following property;

(C) Given an analytic set $A$ in $Y$ and a commutative diagram of holomorphic maps

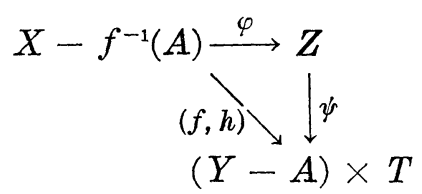

where $\psi$ is light (that is, each fibre is discrete) and $h: X \rightarrow T$ strictly depends on $f$ and $(f, h)$ is a holomorphic map given by $x \mapsto(f(x), h(x))$, and if $K$ is a compact subset of $(Y-A) \times T$, then there exists a compact subset $\widetilde{K}$ of $X-f^{-1}(A)$ such that $\varphi^{-1}(p) \cap \widetilde{K} \neq \varnothing$, for $p \in \psi^{-1}(K) \cap \varphi\left(X-f^{-1}(A)\right)$.

If $f$ satisfies $(C)$, then $f$ satisfies the following $\left(C_{1}\right)$ (we take $A=\varnothing$ and $h=f)$;

$\left(C_{1}\right)$ Given a compact subset $K$ of $Y$ and a commutative diagram of holomorphic maps

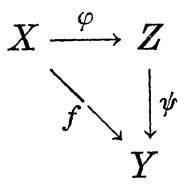

where $\psi$ is light, then there exists a compact subset $\widetilde{K}$ of $X$ such that $\varphi^{-1}(p) \cap \widetilde{K} \neq \varnothing$ for $p \in \psi^{-1}(K) \cap \varphi(X)$.

Note that in such cases, $f, \varphi$, and $(f, h)$ (in the two diagrams above) are naturally semi-proper, and that if $\varphi$ is surjective, $\psi$ is 
proper; in this case $\psi$ is finite! Every $N$-quasi-proper holomorphic map satisfies $(C)$; for, if $f: X \rightarrow Y$ is $N$-quasi-proper, so is $(f, h)$. Thus we have the following inclusion:

$$
\begin{aligned}
\text { proper } & \Longrightarrow \text { quasi-proper } \Longrightarrow N \text {-quasi-proper } \\
& \Longrightarrow(C) \Longrightarrow\left(C_{1}\right) \Longrightarrow \text { semi-proper } .
\end{aligned}
$$

LEMMA 1.1. ([4]) Let $Y$ be a normal analytic space and $f: X \rightarrow Y$ be a proper modification map. If $f$ is nowhere degenerate, then $f$ is a biholomorphic map.

Lemma 1.2. Let $X$ be an irreducible normal analytic space and $f: X \rightarrow Y$ be a nowhere degenerate holomorphic map. If $f$ satisfies $\left(C_{1}\right)$, then $f$ has a complex base $(Z, \varphi)$, and the natural holomorphic map $\psi: Z \rightarrow Y$ with $f=\psi \circ \varphi$ is proper and light.

Proof. $f$ is nowhere degenerate, and so $f$ has a complex base $(Z, \phi)$ (cf. [6]). $f$ is semi-proper, so $f(X)$ is analytic in $Y$ (cf. [1]). Thus we may assume that $f$ is surjective. Since $f$ and $\varphi$ are analytically related and $X$ has a countable basis, $\psi^{-1}(y)=\varphi\left(f^{-1}(y)\right)$ is discrete for $y \in Y$. Thus $\psi$ is light and therefore, is proper, as desired.

2. Proof of theorem. We shall prove our theorem by introducing modification of the proof of the theorem of N. Kuhlmann.

We may assume that $f$ is surjective as in Lemma 1.2, and moreover, that $Y$ is a connected complex manifold since the set of singular points of $Y$ is a thin analytic set in $Y$. By [1], Proposition 1.24, $f\left(E_{f}\right)$ is thin of dimension $\leqq \operatorname{dim} Y-2$.

Let $Y^{\prime}=Y-f\left(E_{f}\right), \quad X^{\prime}=X-f^{-1}\left(f\left(E_{f}\right)\right)$ and $f^{\prime}=f \mid X^{\prime} \rightarrow Y^{\prime}$. Since $f^{\prime}$ satisfies $\left(C_{1}\right)$ and is nowhere degenerate, $f^{\prime}$ has a complex base $\left(Z^{\prime}, \varphi^{\prime}\right)$ and the natural holomorphic map $\psi^{\prime}$ with $f^{\prime}=\psi^{\prime} \circ \varphi^{\prime}$ is proper and light by Lemma 1.2. $Z^{\prime}$ is a normal analytic space. By [5], Satz 1 (or [2], Satz A), we have a (unique up to biholomorphic equivalence) normal analytic space $\widetilde{Z}$ with a holomorphic map $\widetilde{\psi}: \widetilde{Z} \rightarrow Y$ which is proper, light and surjective tuch that $Z^{\prime}=\widetilde{\psi}^{-1}\left(Y^{\prime}\right)$ and $Z^{\prime}$ is dense in $\widetilde{Z}$ and $\psi^{\prime}=\widetilde{\psi} \mid Z^{\prime}$.

We have to show that there exists a surjective holomorphic map $\widetilde{\varphi}: X \rightarrow Z$ such that $(\widetilde{Z}, \widetilde{\varphi})$ is a complex base of $f$.

(a) A holomorphic map $\varphi^{\prime}: X^{\prime} \rightarrow Z^{\prime}$ can uniquely be extended to the surjective holomorphic map $\widetilde{\varphi}: X \rightarrow Z$ such that $\widetilde{\varphi}$ is analytically related to $f$ and $f=\tilde{\psi} \circ \tilde{\varphi}$ : Let $G \subset X \times Y$ be a graph of $f: X \rightarrow Y$ and $G^{\prime} \subset X^{\prime} \times Z^{\prime}$ be a graph of $\phi^{\prime}: X^{\prime} \rightarrow Z^{\prime}$. Let $\iota \times \tilde{\psi}$ : $X \times \widetilde{Z} \rightarrow X \times Y$ be a holomorphic map given by $(x, p) \mapsto(x, \widetilde{\psi}(p))$ and 
$G_{1}:=(\iota \times \widetilde{\psi})^{-1}(G)$. There exists an irreducible branch $\widetilde{G}$ of $G_{1}$ with $\widetilde{G} \cap\left(X^{\prime} \times Z^{\prime}\right)=G^{\prime}$.

The projection $\pi_{1}: \widetilde{G} \rightarrow X$ onto 1st component $X$ is a proper light modification map and therefore, $\pi_{1}$ is biholomorphic by Lemma 1.1. Let $\pi_{2}: \widetilde{G} \rightarrow \widetilde{Z}$ be the projection onto 2nd component $\widetilde{Z}$ and $\widetilde{\varphi}:=$ $\pi_{2} \circ \pi_{1}^{-1}: X \rightarrow \widetilde{Z}$. Then $f=\widetilde{\psi} \circ \widetilde{\phi}$. And since $\widetilde{\psi}$ is light, $\widetilde{\phi}$ is analytically related to $f$. Uniqueness of $\widetilde{\phi}$ is obvious.

(b) Let $h: X \rightarrow T$ be a holomorphic map strictly depending on $f$. Then there exists a (unique) holomorphic map $\psi: \widetilde{Z} \rightarrow T$ such that $h=\dot{\psi} \circ \widetilde{\varphi}$ : Since $f$ satisfies $(C),(\widetilde{\varphi}, h): X \rightarrow \widetilde{Z} \times T$ is semi-proper and therefore, $G_{0}:=(\widetilde{\varphi}, h)(X)$ is analytic in $\tilde{Z} \times T$. Let $\tilde{\pi}_{1}$ and $\tilde{\pi}_{2}$ be projections of $G_{0}$ onto 1st and 2 nd components, respectively. $\pi_{1} \mid G_{0} \cap\left(Z^{\prime} \times T\right) \rightarrow Z^{\prime}$ is a biholomorphic map. In fact, $h^{\prime}:=h \mid X^{\prime}$ strictly depends on $f^{\prime}$ and $\left(Z^{\prime}, \varphi^{\prime}\right)$ is a complex base of $f^{\prime}$, so there exists a holomorphic map $\psi^{\prime \prime}: Z^{\prime} \rightarrow T$ with $h^{\prime}=\psi^{\prime \prime} \circ \varphi^{\prime}$. And then, $G_{0} \cap\left(Z^{\prime} \times T\right)$ is a graph of $\psi^{\prime \prime}$. $h$ strictly depends on $\widetilde{\varphi}$, so $\tilde{\pi}_{1}$ is light. $f$ satisfies $\left(C_{1}\right)$ and $\widetilde{\Phi}=\tilde{\pi}_{1} \circ(\widetilde{\varphi}, h)$, so $\tilde{\pi}_{1}$ is proper. Thus $\tilde{\pi}_{1}: G_{0} \rightarrow \widetilde{Z}$ is a proper light modification map and therefore, it is biholomorphic. Let $\psi:=\tilde{\pi}_{2} \circ \tilde{\pi}_{1}^{-1}: \widetilde{Z} \rightarrow T$, then $h=\psi \circ \widetilde{\varphi}$.

With (a) and (b) we conclude the proof.

\section{REFERENCES}

1. A. Andreotti and W. Stoll, Analytic and algebraic dependence of meromorphic functions, Lecture Notes in Math. 234, Springer (1971).

2. N. Kuhlmann, Niveaumengenräume holomorpher Abbildungen und nullte Bildgarben, Manuscripta Math., 1 (1969), 147-189.

3. - Komplexe Basen zu quasieigentlichen holomorphen Abbildungen, Comm. Math. Helv., 48 (1973), 340-353.

4. R. Remmert, Holomorphe und meromorphe Abbildungen komplexer Räume, Math. Ann., 133 (1957), 328-370.

5. K. Stein, Analytische Zerlegungen komplexer Räume, Math. Ann., 132 (1956), 68-93.

6. Die Existenz komplexer Basen zu holomorphen Abbildungen, Math. Ann., 136 (1958), 1-8.

7. - Maximale holomorphe und meromorphe Abbildungen, I, Amer. J. Math., 85 (1963), 298-315.

Received September 27, 1977.

AKITA UNIVERSITY

AKITA, JAPAN 


\title{
PACIFIC JOURNAL OF MATHEMATICS
}

\section{EDITORS}

RICHARD ARENS (Managing Editor)

University of California

Los Angeles, CA 90024

Charles W. Curtis

University of Oregon

Eugene, OR 97403

C. C. MOORE

University of California

Berkeley, CA 94720

\section{J. DUGUNDJI}

Department of Mathematics University of Southern California Los Angeles, CA 90007

R. Finn and J. Milgram

Stanford University

Stanford, CA 94305

\section{ASSOCIATE EDITORS}
E. F. BECKENBACH
B. H. NeumanN
F. WOLF
K. YOSHIDA

\section{SUPPORTING INSTITUTIONS}

\author{
UNIVERSITY OF BRITISH COLUMBIA \\ CALIFORNIA INSTITUTE OF TECHNOLOGY \\ UNIVERSITY OF CALIFORNIA \\ MONTANA STATE UNIVERSITY \\ UNIVERSITY OF NEVADA, RENO \\ NEW MEXICO STATE UNIVERSITY \\ OREGON STATE UNIVERSITY \\ UNIVERSITY OF OREGON
}

\author{
UNIVERSITY OF SOUTHERN CALIFORNIA \\ STANFORD UNIVERSITY \\ UNIVERSITY OF HAWAII \\ UNIVERSITY OF TOKYO \\ UNIVERSITY OF UTAH \\ WASHINGTON STATE UNIVERSITY \\ UNIVERSITY OF WASHINGTON
}

The Supporting Institutions listed above contribute to the cost of publication of this Journal, but they are not owners or publishers and have no responsibility for its content or policies.

Mathematical papers intended for publication in the Pacific Journal of Mathematics should be in typed form or offset-reproduced, (not dittoed), double spaced with large margins. Please do not use built up fractions in the text of the manuscript. However, you may use them in the displayed equations. Underline Greek letters in red, German in green, and script in blue. The first paragraph or two must be capable of being used separately as a synopsis of the entire paper. Items of the bibliography should not be cited there unless absolutely necessary, in which case they must be identified by author and journal, rather than by item number. Manuscripts, in triplicate, may be sent to any one of the editors. Please classify according to the scheme of Math. Reviews, Index to Vol. 39. All other communications should be addressed to the managing editor, or Elaine Barth, University of California, Los Angeles, California, 90024.

50 reprints to each author are provided free for each article, only if page charges have been substantially paid. Additional copies may be obtained at cost in multiples of 50 .

The Pacific Journal of Mathematics is issued monthly as of January 1966. Regular subscription rate: $\$ 72.00$ a year (6 Vols., 12 issues). Special rate: $\$ 36.00$ a year to individual members of supporting institutions.

Subscriptions, orders for numbers issued in the last three calendar years, and changes of address should be sent to Pacific Journal of Mathematics, P.O. Box 969, Carmel Valley, CA 93924, U.S.A. Older back numbers obtainable from Kraus Periodicals Co., Route 100, Millwood, NY 10546.

PUBLISHED BY PACIFIC JOURNAL OF MATHEMATICS, A NON-PROFIT CORPORATION

Printed at Kokusai Bunken Insatsusha (International Academic Printing Co., Ltd.). 8-8, 3-chome, Takadanobaba, Shinjuku-ku, Tokyo 160, Japan.

Copyright (C) 1978 by Pacific Journal of Mathematics Manufactured and first issued in Japan 


\section{Pacific Journal of Mathematics \\ Vol. 78, No. $2 \quad$ April, 1978}

Su-Shing Chen, Weak rigidity of compact negatively curved manifolds .... 273

Heinz Otto Cordes and D. A. Williams, An algebra of pseudodifferential operators with nonsmooth symbol ....................... 279

Herbert Paul Halpern, Normal expectations and integral decomposition of type III von Neumann algebras ......................... 291

G. Hochschild, On representing analytic groups with their

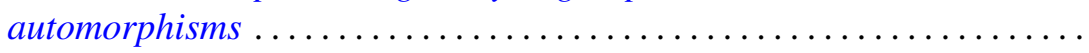

Dean G. Hoffman and David Anthony Klarner, Sets of integers closed under affine operators - the closure of finite sets ....................

Simeon Ivanov, On holomorphic relative inverses of operator-valued

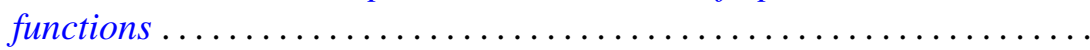

O. P. Juneja and M. L. Mogra, Radii of convexity for certain classes of

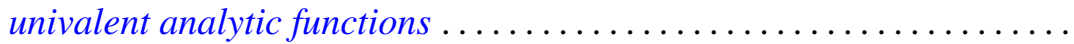

Hadi Kharaghani, The evolution of bounded linear functionals with application to invariant means.......................... 369

Jack W. Macki, A singular nonlinear boundary value problem .......... 375

A. W. Mason and Walter Wilson Stothers, Remarks on a theorem of $L$. Greenberg on the modular group ........................ 385

Kevin Mor McCrimmon, Peirce ideals in Jordan algebras . . . . . . . . . . . 397

John C. Morgan, II, On the absolute Baire property ................ 415

Gerard J. Murphy, Commutative non-Archimedean $C^{*}$-algebras ...

Masafumi Okumura, Submanifolds with L-flat normal connection of the

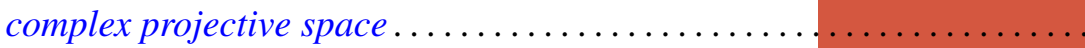

Chull Park and David Lee Skoug, Distribution estimates of barrier-crossing probabilities of the Yeh-Wiener process ...............

Irving Reiner, Invariants of integral representations ........

Phillip Schultz, The typeset and cotypeset of a rank 2 abelian group ..... 503

John Brendan Sullivan, Representations of Witt groups ....

Chia-Chi Tung, Equidistribution theory in higher dimensions . . . 